\title{
Eastern Cooperative Oncology Group Performance Score Is Associated With Survival After Radiotherapy of Bone Metastases from Prostate Cancer
}

\author{
RAPHA HAUS ${ }^{1}$, STEFAN JANSSEN ${ }^{1,2}$, STEVEN E. SCHILD $^{3}$ and DIRK RADES ${ }^{1}$ \\ ${ }^{1}$ Department of Radiation Oncology, University of Lübeck, Lübeck, Germany; \\ ${ }^{2}$ Medical Practice for Radiotherapy and Radiation Oncology, Hannover, Germany; \\ ${ }^{3}$ Department of Radiation Oncology, Mayo Clinic, Scottsdale, AZ, U.S.A.
}

\begin{abstract}
Background/Aim: Understanding prognostic factors of survival are important for treatment personalization in cancer patients. This study aimed to identify such factors for patients irradiated for bone metastases from prostate cancer. Patients and Methods: Data from 74 patients irradiated between 01/2009 and 04/2019 were retrospectively evaluated. Ten characteristics were investigated for survival. Results: Median survival in the entire cohort was 12 months. Survival rates at 3, 6, 9 and 12 months were $84 \%, 73 \%, 56 \%$ and $47 \%$, respectively. On univariate analyses, the Eastern Cooperative Oncology Group (ECOG) performance score of 0-1 was associated with improved survival $(p<0.001)$, absence of visceral metastases $(p=0.099)$ and only one irradiated metastatic site $(p=0.099)$ showed a trend. On Cox regression analysis, only ECOG performance score (risk ratio=3.58, p<0.001) was significant. Conclusion: ECOG performance score is an independent prognostic factor of survival after irradiation of bone metastases from prostate cancer and may allow better personalization of care.
\end{abstract}

Up to $70 \%$ of prostate cancer patients experience bone metastases during the course of their disease (1). Many of these patients receive radiotherapy mainly to relieve pain and to stabilize bones affected by osteolytic lesions (2). For the irradiation of osseous metastases, several dose-fractionation regimens are administered worldwide, including single-

This article is freely accessible online.

Correspondence to: Dirk Rades, Department of Radiation Oncology, University of Lübeck, Ratzeburger Allee 160, 23562 Lübeck, Germany. Tel: +49 45150045401, Fax: +49 45150045404, e-mail: rades.dirk@gmx.net

Key Words: Prostate cancer, bone metastases, multi-fraction irradiation, survival, prognostic factors. fraction radiotherapy, multifraction short-course programs (overall treatment time up to one week) and longer-course programs (usually lasting 2-4 weeks) (2). In cases of uncomplicated bone metastases, i.e. bone metastases without malignant spinal cord compression or an extensive soft-tissue component and/or an (impending) pathological fracture, single-fraction radiotherapy can be recommended for patients with a short survival time (2-4). Unfortunately, recurrent bone pain occurs significantly more often after singlefraction treatment compared to treatment with a multifraction regimen (2-4). Moreover, recalcification of osteolytic bone metastases is more prominent when multiple fractions are used (5). Since significant recalcification can only be expected after several months following radiotherapy, this endpoint is mainly important for patients with more favorable survival prognoses. Also, since the risk of a local recurrence of bone metastases associated with another episode of pain increases with time, this aspect should be considered when treating patients with longer-time expected survival (2-4). Thus, the optimal radiation program for a patient with bone metastases should take into account the predicted remaining lifespan. For predicting a patient's survival independent prognostic factors can be quite valuable. Since cancer types are different with respect to biology, prognosis and patterns of metastatic spread, it is generally agreed that independent prognostic factors should ideally be available for the different cancer types. This study was conducted to identify independent prognostic factors for survival after radiotherapy of bone metastases from prostate cancer.

\section{Patients and Methods}

The data of 74 patients irradiated for bone metastases from prostate cancer between 01/2009 and 04/2019 were retrospectively evaluated. This study was approved by the ethics committee of the University of Luebeck. All 74 patients received multi-fraction longer-course irradiation with i) $10 \times 3$ Gy in 2 weeks $(n=31)$, ii) $12 \times 3$ Gy in 2.5 weeks $(n=1)$, iii) $14-15 \times 2.5$ Gy in 3 weeks $(n=32)$, 
Table I. Distribution of the investigated factors.

\begin{tabular}{lc}
\hline & Number of patients $(\%)$ \\
\hline Age at RT & \\
$\leq 75$ Years & $34(46)$ \\
$\geq 76$ Years & $40(54)$ \\
ECOG performance score & \\
$0-1$ & $40(54)$ \\
$\geq 2$ & $26(35)$ \\
Unknown & $8(11)$ \\
Interval from diagnosis of prostate & \\
cancer to RT of bone metastases & \\
$\leq 24$ Months & $37(50)$ \\
$\geq 25$ Months & $37(50)$ \\
Visceral metastases & \\
No & $53(72)$ \\
Yes & $21(28)$ \\
Further bone metastases & $6(8)$ \\
No & $68(92)$ \\
Yes & \\
Location of metastatic sites & $24(32)$ \\
Spine & $28(38)$ \\
Extraspinal & $22(30)$ \\
Both & \\
Number of irradiated sites & $30(41)$ \\
1 & $44(59)$ \\
$\geq 2$ & $61(82)$ \\
Pathological fracture & $13(92)$ \\
No & \\
Yes & $66(89)$ \\
Upfront surgery of bone metastases & $8(11)$ \\
No & \\
Yes & $64(86)$ \\
Nystemic treatment prior to RT & $1(1)$ \\
Yes & \\
Unknown & \\
\hline & \\
& \\
&
\end{tabular}

RT: Radiotherapy; ECOG: Eastern Cooperative Oncology Group.

iv) $15 \times 2$ Gy in 3 weeks $(n=3)$ or v) $18-20 \times 2.0$ Gy in $3.5-4$ weeks $(\mathrm{n}=7)$. The following ten characteristics (Table I) were investigated with respect to survival: i) age ( $\leq 75 v s . \geq 76$ years), ii) Eastern Cooperative Oncology Group (ECOG) performance score (6) (ECOG 0-1 vs. $\geq 2$ ), iii) interval from diagnosis of prostate cancer to irradiation of bone metastases ( $\leq 24 v s$. $\geq 25$ months, median interval $=24.5$ months), iv) visceral metastases (no vs. yes) or v) further bone metastases (no vs. yes) prior to irradiation of bone metastases, vi) location of metastatic sites (spinal $v s$. extraspinal $v s$. both), vii) number of irradiated metastatic sites ( $1 v s . \geq 2)$, viii) pathological fracture (no vs. yes), ix) upfront surgery of the bone metastases (no $v s$. yes) and $\mathrm{x}$ ) previous systemic treatment prior to irradiation (no vs. yes).

Survival time was referenced from the start of irradiation of the bone metastases. For univariate analyses, the Kaplan-Meier method and the log-rank test were applied. Characteristics that were significant $(p<0.05)$ or showed at least a trend $(p<0.10)$ on univariate analyses were additionally investigated for independence in a multivariate Cox regression analysis.

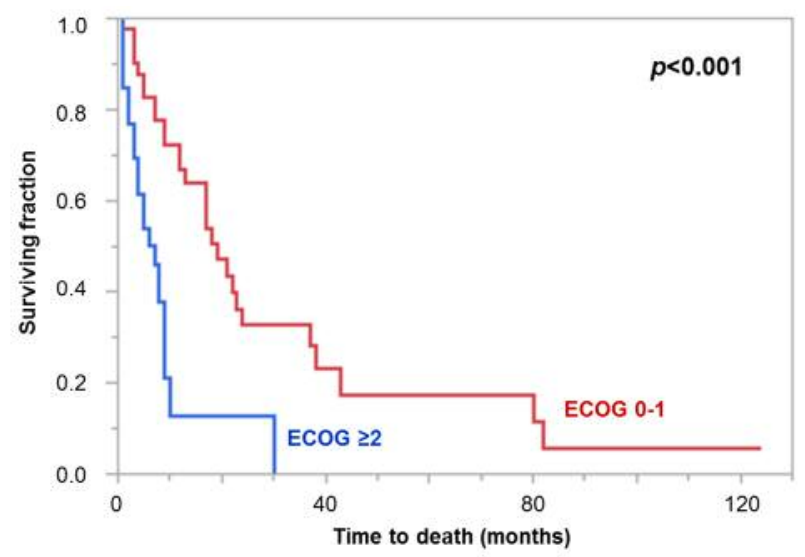

Figure 1. Kaplan-Meier curves for Eastern Cooperative Oncology Group (ECOG) performance scores of 0-1 vs. $\geq 2$.

\section{Results}

Median survival in the entire cohort was 12 months. Survival rates at 3,6, 9 and 12 months were $84 \%, 73 \%, 56 \%$ and $47 \%$, respectively. On univariate analyses, an ECOG performance score of $0-1$ was significantly associated with improved survival (Figure $1, p<0.001$ ). In the absence of visceral metastases $(p=0.099)$ and for only one irradiated metastatic site $(p=0.099)$, a trend towards better survival was found $(p=0.099)$. The data of the univariate analyses are summarized in Table II.

In the Cox regression analysis, the ECOG performance score (risk ratio $=3.43,95 \%$-confidence interval $=1.67-7.12, p<0.001$ ) achieved significance, whereas absence of visceral metastases (risk ratio $=1.07,95 \%$ confidence interval $=0.54-2.05, p=0.83$ ) and one irradiated metastatic site (risk ratio $=1.12,95 \%$ confidence interval $=0.59-2.11, p=0.73$ ) did not.

\section{Discussion}

Prostate cancer is the most common type of cancer in men in industrial nations (1). A considerable number of patients with prostate cancer develop metastases. To improve the prognoses of these patients, novel anticancer drugs have been introduced (7-10). Another approach aiming to improve their outcomes is through personalized care. Personalization of treatment should be based on the patient's individual situation, including his expected survival time. For the estimation of survival prognoses independent prognostic factors are very useful. For patients with prostate cancer, such factors have been identified for other metastatic situations, including brain metastases and malignant spinal cord compression (11-15). The current study was conducted to identify independent prognostic factors for prostate cancer patients with bone metastases. 
Table II. Survival rates of the 11 potential prognostic factors (univariate analysis).

\begin{tabular}{|c|c|c|}
\hline Factor & Survival rates (in \%) at & $p$-Value \\
\hline
\end{tabular}

\begin{tabular}{|c|c|c|c|c|c|}
\hline \multicolumn{6}{|l|}{ Age at RT } \\
\hline$\leq 75$ Years & 88 & 76 & 58 & 46 & \\
\hline$\geq 76$ Years & 80 & 70 & 54 & 49 & 0.61 \\
\hline \multicolumn{6}{|l|}{$\begin{array}{l}\text { ECOG } \\
\text { performance } \\
\text { score }\end{array}$} \\
\hline $0-1$ & 90 & 83 & 72 & 67 & \\
\hline$\geq 2$ & 69 & 50 & 21 & 13 & $<0.001$ \\
\hline $\begin{array}{l}\text { Interval from } \\
\text { diagnosis of } \\
\text { prostate cance } \\
\text { to RT of bone } \\
\text { metastases }\end{array}$ & & & & & \\
\hline$\leq 24$ Months & 89 & 73 & 59 & 48 & \\
\hline$\geq 25$ Months & 78 & 73 & 53 & 47 & 0.66 \\
\hline \multicolumn{6}{|l|}{$\begin{array}{l}\text { Visceral } \\
\text { metastases }\end{array}$} \\
\hline No & 89 & 77 & 60 & 53 & \\
\hline Yes & 71 & 62 & 48 & 33 & 0.099 \\
\hline \multicolumn{6}{|l|}{$\begin{array}{l}\text { Further bone } \\
\text { metastases }\end{array}$} \\
\hline No & 83 & 67 & 67 & 50 & \\
\hline Yes & 84 & 74 & 55 & 47 & 0.93 \\
\hline \multicolumn{6}{|c|}{$\begin{array}{l}\text { Location of } \\
\text { metastatic sites }\end{array}$} \\
\hline Spine & 88 & 79 & 57 & 53 & \\
\hline Extraspinal & 79 & 68 & 54 & 46 & \\
\hline Both & 86 & 73 & 58 & 42 & 0.13 \\
\hline \multicolumn{6}{|l|}{$\begin{array}{l}\text { Number of } \\
\text { irradiated sites }\end{array}$} \\
\hline 1 & 83 & 77 & 70 & 63 & \\
\hline$\geq 2$ & 84 & 70 & 46 & 36 & 0.099 \\
\hline \multicolumn{6}{|l|}{$\begin{array}{l}\text { Pathological } \\
\text { fracture }\end{array}$} \\
\hline No & 82 & 72 & 55 & 48 & \\
\hline Yes & 92 & 77 & 60 & 43 & 0.37 \\
\hline \multicolumn{6}{|c|}{$\begin{array}{l}\text { Upfront surgery } \\
\text { of bone } \\
\text { metastases }\end{array}$} \\
\hline No & 83 & 73 & 57 & 49 & \\
\hline Yes & 88 & 75 & 45 & 30 & 0.23 \\
\hline \multicolumn{6}{|l|}{$\begin{array}{l}\text { Systemic } \\
\text { treatment prior } \\
\text { to RT }\end{array}$} \\
\hline No & 100 & 89 & 63 & 63 & \\
\hline Yes & 81 & 70 & 56 & 46 & 0.58 \\
\hline
\end{tabular}

RT: Radiotherapy; ECOG: Eastern Cooperative Oncology Group; bold $p$-values=significant.

The ECOG performance score was found to be independently associated with survival. This factor can aid physicians when personalizing treatment for patients with osseous metastases from prostate cancer.
Patients with a good performance status (ECOG score of 01) had a favourable prognosis with survival rates of $83 \%$ at 6 months and $67 \%$ at 12 months, respectively. Since many of these patients will live long enough to be at risk of experiencing another episode of bone pain in the irradiated regions, they may be considered for multi-fraction longer-course radiotherapy (2). According to previous meta-analyses, re-treating painful bone metastases was significantly less often required after longercourse than after single-fraction radiotherapy $(3,4)$. Moreover, in a prospective randomized trial, recalcification after longercourse treatment with $10 \times 3$ Gy given over 2 weeks was significantly stronger compared to single-fraction radiotherapy with $1 \times 8$ Gy (5). In this trial, the relative increases in bone density were $173 \%$ compared to $120 \%(p<0.001)$.

On the other hand, patients with a poor performance status (ECOG score of $\geq 2$ ) had much less favorable survival rates of $50 \%$ at 6 months and only $13 \%$ at 12 months, respectively. In two large randomized trials of 1,171 and 765 patients, who were irradiated for painful bone metastases, recurrent bone pain occurred only after a median time of 11 months or $>12$ months, respectively $(16,17)$. Most of the patients with an ECOG performance score of $\geq 2$ will not live long enough to experience a second episode of bone pain and, therefore, appear suitable candidates for single-fraction radiotherapy. When following these considerations and suggestions, one should be aware of the retrospective nature of the data analyzed in this study that may have introduced a hidden selection bias. Although only patients receiving longer-course radiotherapy were included in this study to reduce the risk of a selection bias, the risk of hidden biases remained. Moreover, our suggestions may not be applicable to patients receiving single-fraction radiotherapy, since these patients were not included in the present study. Furthermore, one has to bear in mind that complicated bone metastases, i.e. bone metastases with an (impending) fracture, spinal cord compression or extensive soft-tissue component do generally require radiotherapy with multiple fractions (2).

In conclusion, the ECOG performance score was independently associated with survival. This prognostic factor can guide physicians when personalizing a dosefractionation program for a patient with bone metastases from prostate cancer.

\section{Conflicts of Interest}

On behalf of all authors, the corresponding author states that there are no conflicts of interest related to this study.

\section{Authors' Contributions}

R.H., S.J., S.E.S and D.R. participated in the design of the study. R.H., S.J. and D.R. provided data. D.R. and S.E.S. performed the analyses of the data and drafted the manuscript, which has been reviewed and approved by all authors. 


\section{References}

1 Siegel RL, Miller KD and Jemal A: Cancer statistics, 2019. CA Cancer J Clin 69(1): 7-34, 2019. PMID: 30620402. DOI: $10.3322 /$ caac. 21551

2 Rades D, Schild SE and Abrahm JL: Treatment of painful bone metastases. Nat Rev Clin Oncol 7(4): 220-229, 2010. PMID: 20234353. DOI: $10.1038 /$ nrclinonc.2010.17

3 Wu JS, Wong RK, Lloyd NS, Johnston M, Bezjak A, Whelan T and Supportive Care Guidelines Group of Cancer Care Ontario: Radiotherapy fractionation for the palliation of uncomplicated painful bone metastases - an evidence-based practice guideline. BMC Cancer 4: 71, 2004. PMID: 15461823. DOI: 10.1186/ 1471-2407-4-71

4 Chow E, Zeng L, Salvo N, Dennis K, Tsao M and Lutz S: Update on the systematic review of palliative radiotherapy trials for bone metastases. Clin Oncol (R Coll Radiol) 24(2): 112-124, 2012. PMID: 22130630. DOI: 10.1016/j.clon.2011.11.004

5 Oken MM, Creech RH, Tormey DC, Horton J, Davis TE, McFadden ET and Carbone PP: Toxicity and response criteria of the Eastern Cooperative Oncology Group. Am J Clin Oncol 5(6): 649-655, 1982. PMID: 7165009.

6 Koswig S and Budach V: Remineralization and pain relief in bone metastases after after different radiotherapy fractions (10 times 3 Gy vs. 1 time 8 Gy). A prospective study. Strahlenther Onkol 175(10): 500-508, 1999. PMID: 10554645. DOI: $10.1007 / \mathrm{s} 000660050061$

7 Becker DJ, Iyengar AD, Punekar SR, Ng J, Zaman A, Loeb S, Becker KD and Makarov D: Treatment of metastatic castrationresistant prostate cancer with abiraterone and enzalutamide despite PSA progression. Anticancer Res 39(5): 2467-2473, 2019. PMID: 31092441. DOI: 10.21873/anticanres.13366

8 Kadomoto S, Yaegashi H, Nakashima K, Iijima M, Kawaguchi S, Nohara T, Shigehara K, Izumi K, Kadono Y, Nakajima K and Mizokami A: Quantification of bone metastasis of castrationresistant prostate cancer after enzalutamide and abiraterone acetate using bone scan index on bone scintigraphy. Anticancer Res 39(5): 2553-2559, 2019. PMID: 31092452. DOI: 10.21873/anticanres.13377

9 Ito T, Kanao K, Takahara K, Ando R, Yasui T, Shiroki R, Sumitomo $\mathrm{M}$ and Miyake H: Optimal timing of cabazitaxel introduction for Japanese patients with metastatic castrationresistant prostate cancer. Anticancer Res 39(6): 3089-3094, 2019. PMID: 31177153. DOI: 10.21873/anticanres.13444

10 Chang LW, Hung SC, Wang SS, Li JR, Yang CK, Chen CS, Ho $\mathrm{HC}$, Cheng CL, Ou YC and Chiu KY: Abiraterone acetate and enzalutamide: Similar efficacy in treating post docetaxel metastatic castration-resistant prostate cancer: Single center rxperience. Anticancer Res 39(7): 3901-3908, 2019. PMID: 31262919. DOI: 10.21873/anticanres.13541
11 Dziggel L, Schild SE, Veninga T, Bajrovic A and Rades D: Clinical factors asssociated with treatment outcomes following whole-brain irradiation in patients with prostate cancer. In Vivo 31(1): 35-38, 2017. PMID: 28064217. DOI: 10.21873/invivo. 11021

12 Rades D, Conde-Moreno AJ, Cacicedo J, Segedin B, Veninga T and Schild SE: Metastatic spinal cord compression: A survival score particularly developed for elderly prostate cancer patients. Anticancer Res 35(11): 6189-6192, 2015. PMID: 26504049.

13 Bartscht T and Rades D: Predicting survival after whole-brain irradiation for cerebral metastases from prostate cancer. Anticancer Res 34(8): 4357-4360, 2014. PMID: 25075071.

14 Rades D, Douglas S, Veninga T, Bajrovic A, Stalpers LJ, Hoskin PJ, Rudat V and Schild SE: A survival score for patients with metastatic spinal cord compression from prostate cancer. Strahlenther Onkol 188(9): 802-806, 2012. PMID: 22526228. DOI: $10.1007 / \mathrm{s} 00066-012-0106-3$

15 Weber A, Bartscht T, Karstens JH, Schild SE and Rades D: Survival in patients with metastatic spinal cord compression from prostate cancer is associated with the number of extraspinal organs involved. Anticancer Res 33(10): 4505-4507, 2013. PMID: 24123022.

16 Steenland E, Leer JW, van Houwelingen H, Post WJ, van den Hout WB, Kievit J, de Haes H, Martijn H, Oei B, Vonk E, van der Steen-Banasik E, Wiggenraad RG, Hoogenhout J, WárlámRodenhuis C, van Tienhoven G, Wanders R, Pomp J, van Reijn M, van Mierlo I and Rutten E: The effect of a single fraction compared to multiple fractions on painful bone metastases: a global analysis of the Dutch Bone Metastasis Study. Radiother Oncol 52(2): 101-109, 1999. PMID: 10577695. DOI: 10.1016/ s0167-8140(99)00110-3

17 Bone Pain Trial Working Party (no authors listed): 8 Gy single fraction radiotherapy for the treatment of metastatic skeletal pain: randomised comparison with a multifraction schedule over 12 months of patient follow-up. Bone Pain Trial Working Party. Radiother Oncol 52(2): 111-121, 1999. PMID: 10577696.

Received November 27, 2019

Revised December 9, 2019 Accepted December 16, 2019 